\title{
School Facilities and Student Achievement in Industrial Countries: Evidence from the TIMSS
}

\author{
Arnt O. Hopland ${ }^{1}$ \\ ${ }^{1}$ Department of Economics, Norwegian University of Science and Technology, Norway \\ Correspondance: Arnt O. Hopland, Department of Economics, Norwegian University of Science and Technology, \\ N-7491 Trondheim, Norway. Tel: 47-7359-1654. E-mail: arnt.hopland@svt.ntnu.no
}

\author{
Received: January 23, 2013 Accepted: February 4, 2013 Online Published: February 5, 2013 \\ doi:10.5539/ies.v6n3p162 URL: http://dx.doi.org/10.5539/ies.v6n3p162
}

\begin{abstract}
This paper studies the link between school facilities (buildings and grounds) and student achievement in eight countries using data from the TIMSS 2003 database. The results indicate a negative relationship, but the estimated coefficients are mainly insignificant. Interestingly, the coefficients differ heavily across countries. Whereas there seem to be adverse consequences from poor facilities in Australia, The Netherlands and Japan, there is no significant effect in the remaining five countries. It remains an open question for future research why facilities seem to play such a different role across countries. The main lesson to be learnt from the present investigation is that school facilities seem to have different impact across countries.
\end{abstract}

Keywords: educational production, school facilities

\section{Introduction}

How to create a good learning environment in schools is, for obvious reasons, an important topic in the public debate in all advanced societies. Some are concerned about deteriorating school facilities due to low investment and insufficient maintenance. The present paper is inspired by this debate and aims to study empirically whether or not poor school facilities are associated with poor student achievement in eight industrial countries. The hypothesis is that poor school facilities will have adverse consequences for student achievement and is based on studies suggesting that improved environmental conditions may gain student achievement by reducing distractions and missed school days (Earthman, 2002 and Mendell and Heath, 2005). Some suggest that this may also benefit teachers by improving their morale and reducing absenteeism and turnover, indirectly affecting student achievement (Buckley, Schneider, and Shang, 2005).

These studies provide a set of highly plausible mechanisms through which poor school facilities may affect student achievement. A thorough investigation of these mechanisms is beyond the scope of this paper. Rather, I hypothesize that all these mechanisms should eventually lead to an effect on the students' ability to perform, measured in test scores. Thus, I use survey data on school facilities combined with test scores to explore the hypothesis. The data is obtained from the TIMSS (Trends in International Mathematics and Science Study) 2003 database, which in addition to test scores includes rich survey data. The survey data provides background information regarding the students (including family background), school districts and schools. Among the information about the school is a broad measure of the quality of the school's facilities and I use this measure to generate my key explanatory variables.

There are mainly three studies that are closely related to this paper. First, Cellini, Ferreira, and Rothstein (2010) study effects of investments in school facilities in Californian school districts, using a regression discontinuity design to obtain exogenous variation in the investments. Their main contribution is that they identify a significantly positive effect on housing prices from investment in school facilities. For my purposes, however, the main interest is related to the next step of their investigation. There they study whether the increase in housing prices may be explained by a higher quality on education due to the investments. Interestingly, the long-run effects on student achievement are far from strong enough to explain the effect on housing prices. In fact they draw the conclusion that there is, at best, weak evidence in favor of the hypothesis that increased investment in school facilities will boost student achievement. An interesting implication of their findings is thus that the value of investment in school facilities is not restricted to improvement of scholastic achievement. Second, Neilson and Zimmerman (2011) study a school construction project in Connecticut. They identify a 
significant effect from investment in school facilities of as much as 21 percent of a standard deviation. This is a considerably stronger effect than that found by Cellini et al. (2010), whose point estimates suggest an effect of around 8 percent of a standard deviation. Third, Hopland (2012) studied the link between poor building conditions and student achievement in Norwegian primary schools. His point estimates suggest a negative treatment affect from poor school buildings in the area of 8 percent of a standard deviation, but the treatment is in most cases not statistically significant. The findings suggest that there may be a negative relationship between poor school building conditions and student achievement, but that the link is mostly insignificant. Hence, the studies by Hopland (2012) and Cellini et al. (2010) reach similar conclusions even though they differ substantially both with respect to research questions and empirical strategies.

The stronger effect found by Neilson and Zimmerman (2011) may be due to the fact that they, unlike Cellini et al. (2010) and Hopland (2012), focus specifically on poor school districts. It seems plausible that the effect of investment in school facilities is stronger in poor than in rich districts, because of a poorer initial condition of the facilities. Since this paper does studies industrial countries with no particular emphasis on poor areas, it is reasonable to expect findings that are in line with those found by Cellini et al. (2010) and Hopland (2012) rather than those found by Neilson and Zimmerman.

The present paper is similar to the study based on Norwegian data, since both study the link between a measure of facility conditions and student achievement. A shortcoming with the TIMSS 2003 data compared to the very rich Norwegian data is the limited possibility to control for unobservable characteristics. The rich Norwegian data allows for the use of local government fixed effects to control for unobservable characteristics between local governments and the use of within local government averages to take into account unobservable school characteristics. The present study, on the other hand, has to rely on ordinary least squares (OLS) estimations, which can be severely biased in the presence of unobservable characteristics. It is not given in which direction omitted (unobservable) variables may bias the estimates in this study, as illustrated by the following examples. First, it is unlikely that all characteristics of teacher quality are observable in the data. Thus, if good teachers have a positive effect on student achievement and sort themselves into schools with good facilities, a potential negative effect from facilities will be overestimated. A similar effect will occur if resourceful parents sort their children into schools with good facilities, since it is unlikely that the controls capture all relevant characteristics of the family background and peer effects. Second, compensatory or regressive policies are other potential causes of bias. If policy makers believe that school facilities are important for student achievement, this may lead them to upgrade school facilities where achievements are low. This draws towards underestimation of potential negative effects from poor school facilities. Regressive policies could occur if politicians observe that voters in school districts with poor student achievement are less likely to vote and will tend to bias the estimates in the opposite direction. This problem can, however, be addressed to some extent by looking at how robust the results of interest are to the inclusion of observable control variables.

The main contribution of this paper lies in the possibility to implement exactly the same empirical strategy for several countries. This allows me to investigate if school facilities play a different role in different countries. The results indicate that there are major differences across countries. Whereas there seem to be adverse consequences from poor facilities in Australia, The Netherlands and Japan, there is no significant effect in the remaining five countries, Belgium, Great Britain, Italy, New Zealand, and the USA. The large variation in results indicates that even though Cellini et al. (2010) and Hopland (2012) found roughly zero effects in California and Norway, facilities may play an important role elsewhere. Since resources are scarce, even in rich countries, it is crucial to learn more about how resources are spent most efficiently. If facilities do not seem to play an important role in industrial countries, this may indicate that school facilities in rich countries are too good for them to be a real problem. This would again imply that rich countries better can improve student achievement by prioritizing other parts of the school budget.

In a broader context, this paper is related to the literature studying resource use in schools. Some important factors that come into mind when discussing 'school production', in addition to facilities, are material and teachers. In recent years there has been much emphasis on teachers as an important factor. An example of this is the rich literature studying effects from reductions in class sizes, i.e. decreasing the student/teacher ratio. A few contributions are seminal works by Krueger (1999) and Angrist and Lavy (1999) and a more recent Norwegian study by Leuven, Oosterbeek, and Rønning (2008). These are important studies since it will be fairly easy to reduce class sizes if it turns out to be an effective tool. However, the costs will be quite high since the need for more teachers and instructional space will lead to a cost increase roughly proportional to the reduction of class size. Interestingly, the literature is far from conclusive. Some studies identify significantly positive effects from reducing class size (Krueger, 1999 and Angrist and Lavy, 1999), whereas other studies reject even small effects 
(Leuven et al., 2008). Improving school facilities is similar to reducing class size in two important ways. First, both will involve considerable costs, so thorough investigations regarding their impact on student achievement are necessary. Second, if they are found to be effective, both will be fairly easy to implement for policy makers, at least compared to more complex policies, e.g. to "increase teacher quality".

The remainder of the paper is organized as follows: In Section 2 I present and examine the data. The empirical strategy is discussed in Section 3 before the results are presented in Section 4. The findings of the paper are summarized in Section 5.

\section{A First Look at the Data}

The dataset consists of $4^{\text {th }}$ grade students from four Western European countries ((Flemish) Belgium, Great Britain (GB in the tables), Italy and The Netherlands) and four non-European countries (Australia, Japan, New Zealand (NZL in the tables), and the USA) representing a broad specter of highly developed industrial countries. (Note 1). Each country draws the participating schools from a stratified sample, to ensure a representative sample of schools. Further, within each of the schools, generally one class from the $4^{\text {th }}$ grade is randomly chosen to get a representative student sample. (Note 2). The database, in addition to test results, includes rich information from questionnaires answered by students, teachers and principals. From these I obtain the key explanatory variables and control variables used in the analysis.

The key explanatory variables are based on the following question from the principals' questionnaire: Is your school's capacity to provide instruction affected by a shortage or inadequacy of school buildings and grounds? (Question 23c). The following answers are possible: 1: none, 2: a little, 3: some or 4: a lot. The question provides a very broad definition of the quality of the physical learning environment. Importantly, the questionnaire contains other questions that capture equipment, such as computers and instructional material. Thus, this specific question should only capture aspects directly related to the facilities. There is, however, still a variety of cases where a principal may report that school facilities are inadequate. Some examples are if the classrooms are too small or too few or if the building itself is too small or in poor condition.

The very broad formulation of the question may be open for different interpretations across respondents. For example, what may be considered as flawless facilities in one place may be considered to be poor elsewhere. The difference in interpretation is likely to be large between poor and rich countries, making comparison of results difficult. Thus I have chosen to only include rich and democratic market economies. Since the countries are treated separately in the analysis, the most important thing is that the principals in each country have a similar interpretation of the question. However, when discussing the results across countries, it will be useful if the understanding, in large, is similar also across countries.

Two interesting differences between the measures used in this study compared to that used in Hopland (2012) should be noted. First, the Norwegian measure is based on a technical building condition index that may capture technical issues that do not have a direct impact on the students' learning environment. The question used in the TIMSS on the other hand, specifically aims to identify problems that affect the "capacity to provide instruction". Second, the Norwegian measure does not capture "shortage" of facilities, only the technical condition of the facilities available. Thus, one could argue that the measure in the TIMSS is more relevant for studies of student achievement. The one used in Hopland (2012) does, however, have the advantage that it is a highly standardized scale, reducing the potential for different interpretation of the scale across respondents.

In the empirical specification I will use two different formulations based on the facility index. First, I will apply a flexible formulation where I include dummies for each of the categories, using the best facilities as reference category. Second, I will introduce a poor facilities dummy (pfac) which equals one if the school is reported to be in category 2, 3 or 4 . (Note 3 ). I then simply compare all schools with good facilities to those which have unsatisfying facilities, asking: Are poor school facilities associated with poor student achievement?

Since the key explanatory variables are based on a Likert scale, it is likely that they will contain some level of measurement errors. It is well known that measurement errors in the explanatory variables lead to an attenuation bias. However, since the principal should have close to perfect information regarding the situation at his/her school, this need not be a critical shortcoming for this study. A second point to be emphasized is that since the schools cannot be identified, the principals should have no incentives for strategic reporting. An example of strategic reporting would be to report that school facilities are poor if the principal expects the students in his/her school to have poor achievement on the test. Such strategic reporting could lead to a reverse causality problem, but it seems not likely to be the case. 
The upper part of Table 1 summarizes the percentage of schools reported to be in each of the categories. Importantly, there is sufficiently spread along the categories to give meaningful variation, even though all countries have a majority of their schools in category 1 or 2 . The observation that most schools are in fairly good condition is not very surprising given that the study targets wealthy countries exclusively. In the analysis I use the best category as reference. The reader will note that New Zealand has by far most schools in this category (62 percent) in front of the USA (54 percent) and Japan (51 percent). Italy has the smallest proportion of schools in the best category with only 26 percent of the schools. In the lower part of Table 1 I report descriptive statistics for the poor facilities dummy. Note that the dummy is not exactly identical to one minus the share of schools in the best category. This is because the dummy is calculated on the student level and reflects that the schools in the survey vary in size.

In TIMSS, student performance in mathematics and science is tested separately using international achievement scores with an international mean of 500 and an international standard deviation of 100. Summary statistics for the test scores are reported in Table 2 . The countries in the sample seem to be fairly even. Further, all countries are above the international average for at least one of the tests. Australia and New Zealand are both marginally below 500 on the mathematics test, the remaining are above the international average for both tests.

Table 1. School facilities. Based on the question: Is your school's capacity to provide instruction affected by a shortage or inadequacy of school buildings and grounds?

\begin{tabular}{|c|c|c|c|c|c|c|c|c|}
\hline \multicolumn{9}{|l|}{ Distribution of answers } \\
\hline & Australia & Belgium & GB & Italy & Japan & Netherlands & NZL & USA \\
\hline None (Cat 1) & $44 \%$ & $49 \%$ & $37 \%$ & $26 \%$ & $51 \%$ & $36 \%$ & $62 \%$ & $54 \%$ \\
\hline A little (Cat 2) & $26 \%$ & $23 \%$ & $37 \%$ & $26 \%$ & $37 \%$ & $20 \%$ & $24 \%$ & $23 \%$ \\
\hline Some (Cat 3) & $20 \%$ & $16 \%$ & $18 \%$ & $33 \%$ & $8 \%$ & $29 \%$ & $10 \%$ & $17 \%$ \\
\hline A lot (Cat 4) & $10 \%$ & $12 \%$ & $8 \%$ & $15 \%$ & $4 \%$ & $15 \%$ & $4 \%$ & $6 \%$ \\
\hline No. of schools & 200 & 146 & 206 & 171 & 150 & 118 & 213 & 221 \\
\hline Pfac & 0.58 & 0.49 & 0.61 & 0.77 & 0.48 & 0.64 & 0.37 & 0.44 \\
\hline (St.dev) & $(0.49)$ & $(0.50)$ & $(0.49)$ & $(0.42)$ & $(0.50)$ & $(0.48)$ & $(0.48)$ & $(0.50)$ \\
\hline Observations (students) & 5134 & 9857 & 7296 & 4282 & 5322 & 2673 & 8298 & 16377 \\
\hline
\end{tabular}

Table 2. Summary statistics for the test scores

\begin{tabular}{|c|c|c|c|c|c|c|c|c|c|c|c|c|c|c|c|c|}
\hline & Australia & & Belgium & & $\underline{\mathrm{GB}}$ & & Italy & & Japan & & Netherlands & & NZL & & $\underline{\text { USA }}$ & \\
\hline & Math & Science & Math & Science & Math & Science & Math & Science & Math & Science & Math & Science & Math & Science & Math & Science \\
\hline Average score & 499.55 & 523.89 & 551.95 & 520.35 & 509.47 & 519.42 & 501.32 & 514.22 & 565.60 & 544.70 & 541.92 & 526.05 & 494.33 & 520.03 & 512.49 & 528.74 \\
\hline (Standard deviation) & (75.54) & $(75.31)$ & $(54.83)$ & (49.65) & $(82.16)$ & (79.16) & (78.85) & $(80.81)$ & $(70.27)$ & $(68.87)$ & 50.62 & (47.69) & $(81.60)$ & (82.03) & $(73.81)$ & (78.13) \\
\hline Observations & 5219 & 5219 & 10067 & 10067 & 8757 & 8757 & 4282 & 4282 & 5322 & 5322 & 2937 & 2937 & 8502 & 8502 & 18448 & 18448 \\
\hline
\end{tabular}

\section{Empirical Strategies}

I start out by estimating a standard school production function using OLS

$$
y_{i j}=\gamma_{0}+\mathbf{b}_{j} \gamma_{b}+\mathbf{Z}_{i j} \gamma_{z}+\mathbf{X}_{j} \gamma_{x}+u_{i j}
$$

where $y_{i j}$ is the test score for student $i$ in school $j$, the vector $\mathbf{b}_{j}$ includes the measure(s) of school facilities and the vector $\gamma_{b}$ includes the coefficient(s) of interest. $\gamma_{0}$ is a constant term while $u_{i j}$ is the error term. In addition to the key explanatory variable(s), I include two vectors with control variables.

The vector $\mathbf{Z}_{i j}$ includes observable student characteristics and family background. The student characteristics include a dummy which equals one if the student is a girl and a dummy indicating whether the student is native to the country. The family background variables include a dummy indicating whether the student's father is a foreigner and an index indicating the approximate number of books in the family's home. The latter of these can be considered as a proxy for the educational level in the home and the socio-economic status of the family.

$\mathbf{X}_{j}$ is a vector of school specific controls. When studying the effects from a specific resource, it is essential to control for other important resources, notably teachers. On the one hand, schools that spend a lot on facilities may spend much in general and thus recruit a large staff of highly qualified teachers. On the other hand, there 
can be a substitution effect. In this case schools that spend a lot on its facilities have to reduce other spending, and thus reduce their teaching staff or hire less qualified teachers. Anyway, it is essential to control for teaching capacity and quality. Thus I include the number of students in the mathematics or science class, depending on which test is analyzed, and a dummy indicating whether the school suffers from a shortage of teachers. (Note 4). These capture whether the school is capable of attracting a sufficient amount of teachers. Further, I include a set of teacher characteristics in order to capture the quality of the teachers. These include the length of the teacher's education, a dummy indicating whether or not the teacher has a licence to teach and the teacher's tenure. Finally, I acknowledge that also the socio-economic status of the population in the school district may be correlated with both student achievement and facility conditions. Hence, to account for peer group effects I include the share of economically disadvantaged and economically affluent families with children in the school. Descriptive statistics and closer definitions of the control variables are presented in the Appendix Table A1.

\section{Results}

Tables 4 and 5 present results from the OLS regressions. In the regressions in the upper part of the tables, I use the flexible three-dummy formulation, while I in the lower part only include the poor facilities dummy. The first observation to be made is that the dummies are in general negative, but mostly insignificant. In the simple regressions (Table 4) the reader will observe negative estimates in the three-dummy formulation in Australia, Belgium, The Netherlands and the US. It is, however, not a clear pattern where the test scores fall as the facilities deteriorate. As an example, the reader will see that in the US, the only significantly negative estimate is for the second best category. The interpretation is thus not straightforward, except that flawless schools may be better than schools with any level of unsatisfying facilities. When looking at the one-dummy formulation, only two of the countries get significant estimates for the poor facilities dummy, Australia (math) and Japan (science). Because of the intuitively appealing interpretation, I use this formulation as base for numerical examples of the effects. In Australia, moving from poor to good facilities is predicted to boost test scores in math by close to 15 percent of a standard deviation. In Japan, the predicted effect on science test scores is roughly 9 percent of a standard deviation. The coefficients are, however, not very precisely estimated, and are significant only at the 10 percent level for both countries.

When looking at the results for the multiple regressions (Table 5), it is interesting to observe that the coefficients that were most precisely estimated in the simple regressions do not change dramatically. The fact that the coefficients for the poor facilities dummy do not change much when excluding the controls is interesting. This may also indicate that they are not necessarily very sensitive to unobservable characteristics related to these. (Note 5). This observation is consistent with the results in Hopland (2012). As mentioned in the Introduction, the study on Norwegian data also concluded that the OLS estimates were not sensitive to unobservable characteristics. This is, of course, not to be interpreted as evidence that OLS provides unbiased estimates in the present study. As a consequence, the point estimates should be interpreted with some caution.

The reader will observe that the most important change when going from simple to multiple regressions is that there are some more significant estimates, both in the three-dummy and the one-dummy formulation. In the three-dummy formulation the reader will observe significantly negative estimates for Australia, Italy, Japan, the Netherlands and the US. When looking at the one-dummy formulations, significant coefficients for the pfac dummy in the Australian, Dutch and Japanese samples can be seen.

In the Australian data, the coefficients for the poor facilities dummy are significant also when estimating science test scores. The coefficient does not change much from the simple regressions. However, a slight increase in coefficient value, combined with a drop in standard errors just makes it significant at the 10 percent level. The coefficient when estimating the math test scores drops slightly, but is still significant at the 10 percent level. The predicted effect in terms of standard deviations by going from poor to good facilities is an increase by roughly 14 percent and 12 percent for math and science, respectively.

The coefficient for poor facilities is also significant when estimating both test scores in the Dutch sample. The significant coefficients in the multiple regressions are not very different from the insignificant coefficients in the simple regressions, but are more precisely estimated. The predicted effect in terms of standard deviations by going from poor to good facilities is an increase by roughly 11 percent for both math and science. As in Australia, the coefficients are significant only at the 10 percent level. Still, the Dutch and Australian results provide the strongest support for the hypothesis, since we observe significantly negative effects from poor facilities on both tests.

When estimating the Japanese test scores I only find significant effects from the poor facilities dummy on test scores in science. The coefficient value indicates a negative treatment effect from poor facilities of roughly 9 
percent of a standard deviation. The coefficient is more precisely estimated than in the simple regressions and is now significant at the 5 percent level. However, even though the effect seems fairly strong when estimating science test scores, it can also be noted that the estimated effect on the test scores in mathematics is not significant. Thus, the results for Japan are only providing weak support for the hypothesis that school facilities matter for student achievement.

For the remaining 5 countries there are no significant coefficients in the restrictive one dummy formulation. The results differ quite heavily across the different countries and are also very imprecisely estimated, typically with t-values well below one in absolute value. Thus it is difficult to identify any clear patterns for these countries.

The tendency towards a negative relationship, but low significance is largely in line with the findings in Cellini et al. (2010) and Hopland (2012). However, it is interesting to note that there is quite a lot of variation across countries. This clarifies the contribution of this paper relative to the more geographically constrained analyses in the papers by Cellini et al. (California) and Hopland (Norway). It is, however, hard to identify any clear patterns in my data that could explain the difference in results across the countries. The three countries where some effects are identified are not on the same continent. Further, they do not stand out in any way when looking at the test scores (Table 2). Looking at the distribution of school facilities (Table 1) does not make us much wiser either. Whereas the Netherlands have the second highest proportion of schools in the worst category, Japan and Australia are around the middle of the distribution, with the third and fifth lowest proportion in the worst category, respectively.

Table 3. Estimation of test results. OLS without controls

\begin{tabular}{|c|c|c|c|c|c|c|c|c|c|c|c|c|c|c|c|c|}
\hline & $\underline{\text { Australia }}$ & & Belgium & & $\underline{\mathrm{GB}}$ & & Italy & & $\underline{\text { Japan }}$ & & Netherlands & & $\underline{\mathrm{NZL}}$ & & $\underline{\text { USA }}$ & \\
\hline \multirow[t]{2}{*}{ Variables } & (A) & (B) & (C) & (D) & (E) & (F) & (G) & $(\mathrm{H})$ & (I) & (J) & $(\mathrm{K})$ & (L) & (M) & $(\mathrm{N})$ & (O) & (P) \\
\hline & Math & Science & Math & Science & Math & Science & Math & Science & Math & Science & Math & Science & Math & Science & Math & Science \\
\hline \multirow[t]{2}{*}{ Cat2 (second best) } & -0.769 & -0.140 & 2.596 & 3.969 & -0.171 & 2.167 & -16.48 & -14.42 & -0.708 & -5.429 & -1.504 & -2.103 & 5.504 & 4.989 & $-13.90^{*}$ & -5.385 \\
\hline & $(7.207)$ & $(6.721)$ & $(3.533)$ & $(2.982)$ & (7.867) & $(7.283)$ & $(10.34)$ & $(10.73)$ & $(5.136)$ & $(4.069)$ & $(5.034)$ & $(4.808)$ & $(8.623)$ & (8.154) & $(7.659)$ & $(8.523)$ \\
\hline \multirow[t]{2}{*}{ Cat3 } & $-23.23^{* *}$ & $-19.79 * *$ & 3.981 & 2.878 & 7.603 & 10.31 & 3.520 & 5.647 & -0.527 & -7.590 & $-10.52^{*}$ & -8.030 & 7.128 & 6.027 & 1.781 & -2.056 \\
\hline & $(9.322)$ & $(7.980)$ & $(4.762)$ & $(4.141)$ & $(8.859)$ & $(9.153)$ & (11.07) & (11.67) & $(5.393)$ & $(6.651)$ & $(6.097)$ & $(5.285)$ & $(8.879)$ & $(9.164)$ & $(6.947)$ & (7.767) \\
\hline \multirow[t]{2}{*}{ Cat4 (worst) } & $-14.46^{*}$ & -6.670 & $-17.72^{* *}$ & -10.17 & -11.11 & -13.24 & -3.784 & 0.607 & -11.08 & -12.11 & -4.720 & -3.580 & 19.27 & 14.88 & -13.83 & -15.71 \\
\hline & $(7.761)$ & $(7.655)$ & $(8.501)$ & $(7.228)$ & $(24.12)$ & $(24.19)$ & $(13.44)$ & $(14.05)$ & $(8.784)$ & $(8.382)$ & $(6.041)$ & $(5.281)$ & (11.86) & $(13.23)$ & $(16.45)$ & $(17.25)$ \\
\hline R-squared & 0.015 & 0.010 & 0.014 & 0.007 & 0.003 & 0.006 & 0.010 & 0.010 & 0.001 & 0.003 & 0.007 & 0.005 & 0.003 & 0.002 & 0.007 & 0.003 \\
\hline \multirow[t]{2}{*}{ Pfac } & $-11.22 *$ & -8.108 & -1.811 & 0.168 & 0.128 & 1.825 & -5.149 & -2.517 & -1.697 & $-6.482 *$ & -6.142 & -5.004 & 7.223 & 6.187 & -7.738 & -5.601 \\
\hline & $(6.281)$ & (5.743) & (3.713) & (3.156) & (7.944) & (7.647) & (9.854) & $(10.33)$ & $(4.214)$ & $(3.555)$ & (4.299) & (3.772) & $(6.848)$ & $(6.637)$ & $(6.082)$ & $(6.623)$ \\
\hline R-squared & 0.005 & 0.003 & 0.000 & 0.000 & 0.000 & 0.000 & 0.001 & 0.000 & 0.000 & 0.002 & 0.003 & 0.003 & 0.002 & 0.001 & 0.003 & 0.001 \\
\hline No. of schools & 200 & 200 & 146 & 146 & 206 & 206 & 171 & 171 & 150 & 150 & 118 & 118 & 213 & 213 & 221 & 221 \\
\hline No. of students & 5,134 & 5,134 & 9,857 & 9,857 & 7,296 & 7,296 & 4,282 & 4,282 & 5,322 & 5,322 & 2,673 & 2,673 & 8,298 & 8,298 & 16,377 & 16,377 \\
\hline
\end{tabular}

Robust standard errors (adjusted for school level clustering) in parentheses.

$* * * \mathrm{p}<0.01, * * \mathrm{p}<0.05, * \mathrm{p}<0.1$.

Constant term (not reported) included. 
Table 4. Estimation of test results. OLS

\begin{tabular}{|c|c|c|c|c|c|c|c|c|c|c|c|c|c|c|c|c|}
\hline \multirow{3}{*}{ Variables } & \multicolumn{2}{|l|}{$\underline{\text { Australia }}$} & \multicolumn{2}{|l|}{$\underline{\text { Belgium }}$} & \multicolumn{2}{|l|}{$\underline{\mathrm{GB}}$} & \multicolumn{2}{|l|}{$\underline{\text { Italy }}$} & \multicolumn{2}{|l|}{ Japan } & \multicolumn{2}{|l|}{$\underline{\text { Netherlands }}$} & \multicolumn{2}{|l|}{ NZL } & \multicolumn{2}{|l|}{$\underline{\text { USA }}$} \\
\hline & (A) & (B) & (C) & (D) & (E) & (F) & (G) & (H) & (I) & (J) & $(\mathrm{K})$ & (L) & (M) & $(\mathrm{N})$ & $(\mathrm{O})$ & (P) \\
\hline & Math & Science & Math & Science & Math & Science & Math & Science & Math & Science & Math & Science & Math & Science & Math & Science \\
\hline \multirow[t]{2}{*}{ Cat2 (second best) } & -7.333 & -7.747 & 0.578 & 1.125 & 1.899 & 2.855 & $-18.11^{*}$ & -15.32 & 1.168 & $-5.327^{*}$ & $-6.159^{*}$ & $-7.326^{*}$ & -0.173 & 7.393 & $-8.436^{*}$ & 1.279 \\
\hline & (7.127) & $(5.929)$ & (3.058) & $(2.888)$ & $(6.798)$ & $(6.264)$ & (10.26) & (11.08) & $(4.370)$ & (3.149) & $(3.276)$ & (3.813) & $(6.767)$ & $(4.806)$ & $(4.502)$ & $(4.585)$ \\
\hline \multirow[t]{2}{*}{ Cat3 } & $-18.14^{* *}$ & $-14.71^{* *}$ & 5.275 & 4.195 & 7.012 & 7.420 & 2.747 & 6.367 & -1.825 & $-10.77^{*}$ & -1.426 & -0.715 & -0.298 & -3.154 & 3.054 & 1.252 \\
\hline & $(7.713)$ & $(7.261)$ & $(4.254)$ & (3.586) & $(9.700)$ & (7.968) & $(10.75)$ & (11.41) & $(6.456)$ & $(5.655)$ & $(3.852)$ & (3.799) & (7.365) & $(7.072)$ & $(4.842)$ & $(5.051)$ \\
\hline \multirow[t]{2}{*}{ Cat4 (worst) } & -6.181 & -2.502 & -2.486 & 5.020 & 9.328 & 2.507 & -3.249 & 3.764 & -0.890 & -2.271 & $-9.349^{*}$ & $-8.995^{*}$ & 1.809 & -8.217 & -12.11 & $-15.20^{*}$ \\
\hline & (7.162) & $(6.316)$ & $(5.569)$ & $(4.390)$ & $(9.346)$ & $(9.831)$ & (14.04) & $(14.81)$ & $(5.785)$ & (6.119) & $(5.168)$ & (4.564) & (11.38) & $(10.24)$ & $(8.329)$ & (8.514) \\
\hline R-squared & 0.159 & 0.152 & 0.130 & 0.116 & 0.234 & 0.214 & 0.077 & 0.080 & 0.085 & 0.070 & 0.162 & 0.159 & 0.223 & 0.164 & 0.297 & 0.312 \\
\hline \multirow[t]{2}{*}{ Pfac } & $-10.71^{*}$ & $-8.986^{*}$ & 1.497 & 3.043 & 3.774 & 3.895 & -5.894 & -1.810 & 0.497 & $-5.918^{* *}$ & $-5.387^{*}$ & $-5.434^{*}$ & -0.00170 & 2.203 & -4.937 & -1.772 \\
\hline & $(5.638)$ & $(4.981)$ & $(2.771)$ & $(2.460)$ & $(6.684)$ & (5.919) & $(9.942)$ & $(10.71)$ & (3.753) & $(2.853)$ & $(2.955)$ & (3.010) & $(5.066)$ & (4.694) & (3.709) & (3.746) \\
\hline R-squared & 0.156 & 0.150 & 0.129 & 0.116 & 0.234 & 0.213 & 0.067 & 0.069 & 0.085 & 0.069 & 0.159 & 0.155 & 0.223 & 0.161 & 0.294 & 0.310 \\
\hline Student/family controls & + & + & + & + & + & + & + & + & + & + & + & + & + & + & + & + \\
\hline School district controls & + & + & + & + & + & + & + & + & + & + & + & + & + & + & + & + \\
\hline Teacher controls & + & + & + & + & + & + & + & + & + & + & + & + & + & + & + & + \\
\hline Social controls & + & + & + & + & + & + & + & + & + & + & + & + & + & + & + & + \\
\hline No. of schools & 156 & 155 & 134 & 134 & 119 & 120 & 171 & 171 & 136 & 137 & 96 & 96 & 171 & 156 & 172 & 168 \\
\hline No. of students & 3,150 & 3,026 & 4,360 & 4,251 & 3,488 & 3,465 & 3,848 & 3,848 & 3,843 & 3,879 & 1,985 & 1,985 & 2,469 & 2,250 & 10,562 & 10,234 \\
\hline
\end{tabular}

Robust standard errors (adjusted for school level clustering) in parentheses.

$* * * \mathrm{p}<0.01, * * \mathrm{p}<0.05, * \mathrm{p}<0.1$.

Constant term (not reported) included.

\section{Summary}

This paper has studied the link between the condition of school facilities and student achievement in eight countries and is based on data from the TIMSS 2003 database. The OLS estimates indicate that there may be a negative link between poor school facilities and student achievement. However, the results vary heavily across countries. Whereas there seem to be adverse consequences from poor facilities in Australia, The Netherlands and Japan, there is no significant effect in the remaining five countries. It remains an open question for future research why facilities seem to play such a different role across countries.

The main lesson to be learnt from the present investigation is that school facilities seem to have different impact across countries. Even though the findings for most countries are similar to the findings in Cellini et al. (2010) and Hopland (2012) there is also some interesting deviations. Thus it would be premature to conclude that the condition of school facilities is not a critical factor for student achievement. Rather, future research should dig deeper and investigate under which circumstances (if any) facility conditions do play a crucial role.

\section{Acknowledgements}

I would like to thank participants at the 2012 Scottish Economic Society Conference, 2011 Meeting of the Norwegian Economic Association and seminar participants at the Norwegian University of Science and Technology (NTNU) for useful suggestions. I am also grateful for comments on earlier drafts of the paper from Manudeep Singh Bhuller, Lars-Erik Borge, Kåre Johansen, Katrine Løken, Bjarne Strøm, and John Marius Ørke. This paper is part of a project funded by the Norwegian Ministry of Local Government and Regional Development. The author bears the full responsibility for the analysis and the conclusions that are drawn.

\section{References}

Altonji, J. G, Elder, T. E, \& Taber, C. R. (2005). Selection on Observed and Unobserved Variables: Assessing the Effectiveness of Catholic Schools. Journal of Political Economy, 113, 151-184 http://dx.doi.org/10.1086/426036

Angrist, J. D., \& Lavy, V. (1999). Using Maimonides' rule to estimate the effect of class size on scholastic achievement. Quarterly Journal of Economics, 114, 533-75. http://dx.doi.org/10.1162/003355399556061 
Beaton, A. E., Mullis, I. V. S., Martin, M. O., Gonzales, E. J., Kelly, D. L., \& Smith, T. A. (1996). Mathematics Achievement in the Middle School Years: IEA's Third International Mathematics and Science Study (TIMSS). Chestnut HILL, MA: Boston College

Buckley, J., Schneider, M., \& Shang, Y. (2005). "Fix It and They Might Stay: School Facility Quality and Teacher Retention in Washington D. C. The Teachers College Record, 107, 1107-1123. http://dx.doi.org/10.1111/j.1467-9620.2005.00506.x

Cellini, S. R., Ferreira, F., \& Rothstein, J. (2010). The Value of School Facility Investments: Evidence from a Dynamic Regression Discontinuity Design. Quarterly Journal of Economics, 125, 215-261. http://dx.doi.org/10.1162/qjec.2010.125.1.215

Earthman, G. I. (2002). School Facility Conditions and Student Academic Achievement. UCLA's Institute for Democracy, Education and Acces (IDEA) Paper no. wws-rr008-1002

Hopland, A. O. (2012). School building conditions and student achievement: Norwegian evidence. Working Paper No. 2/2012, Department of Economics, Norwegian University of Science and Technology.

Krueger, A. (1999). Experimental estimates of education production functions. Quarterly Journal of Economics, 114, 497-532. http://dx.doi.org/10.1162/003355399556052

Leuven, E., Oosterbeek, H., \& Rønning, M. (2008). Quasi-experimental Estimates of the Effect of Class Size on Achievement in Norway. Scandinavian Journal of Economics, 110, 663-693. http://dx.doi.org/10.1111/j.1467-9442.2008.00556.x

Martin, M. O., \& Kelly, D. L. (Eds.) (1997). Third International Mathematics and Science Study Technical Report, Volume II: Implementation and Analysis - Primary and Middle School Years. Chestnut Hill, MA: Boston College.

Mendell, M. J., \& Heath, G. A. (2005). Do indoor pollutants and thermal conditions in schools influence student performance? A critical review of the literature. Indoor Air, 15, 27-52. http://dx.doi.org/10.1111/j.1600-0668.2004.00320.x

Neilson, C., \& Zimmerman, S. (2011). The Effect of School Construction on Test Scores, School Enrollment, and Home Prices. IZA DP 6106, 2011.

TIMSS. (2003). Retrieved from http://timss.bc.edu/timss2003.html

\section{Appendix: Appendix Tables}

Table A1. Descriptive statistics. Control variables

\begin{tabular}{lllllllll}
\hline VARIABLES & Australia & Belgium & GB & Italy & Japan & Netherlands & NZL & USA \\
\hline Books & 3.46 & 3.00 & 3.21 & 2.62 & 2.77 & 3.10 & 3.22 & 2.95 \\
& $(1.16)$ & $(1.07)$ & $(1.24)$ & $(1.20)$ & $(1.07)$ & $(1.14)$ & $(1.18)$ & $(1.22)$ \\
Observations & 5090 & 9857 & 8537 & 4229 & 5290 & 2878 & 8289 & 18067 \\
\hline Native & 0.84 & 0.93 & 0.84 & 0.96 & 0.98 & 0.93 & 0.84 & 0.79 \\
& $(0.36)$ & $(0.25)$ & $(0.36)$ & $(0.20)$ & $(0.12)$ & $(0.25)$ & $(0.37))$ & $(0.41)$ \\
Observations & 4925 & 9867 & 8492 & 3943 & 5240 & 2812 & 6909 & 18124 \\
\hline Foreign father & 0.30 & 0.15 & 0.14 & 0.08 & 0.01 & 0.16 & 0.28 & 0.25 \\
& $(0.46)$ & $(0.35)$ & $(0.34)$ & $(0.27)$ & $(0.10)$ & $(0.37)$ & $(0.45)$ & $(0.43)$ \\
Observations & 4584 & 9817 & 8401 & 4110 & 5083 & 2715 & 6803 & 17872 \\
\hline Girl & 0.50 & 0.50 & 0.50 & 0.48 & 0.49 & 0.49 & 0.49 & 0.50 \\
& $(0.50)$ & $(0.50)$ & $(0.50)$ & $(0.50)$ & $(0.50)$ & $(0.50)$ & $(0.50)$ & $(0.50)$ \\
Observations & 5219 & 10067 & 8757 & 4282 & 5322 & 2937 & 8502 & 18448 \\
\hline Number of students in math class & 26.31 & 20.58 & 27.98 & 20.33 & 32.69 & 23.94 & 27.47 & 23.59 \\
& $(6.32)$ & $(4.44)$ & $(6.10)$ & $(4.10)$ & $(5.60)$ & $(5.71)$ & $(5.05)$ & $(5.45)$ \\
Observations & 4553 & 4938 & 6022 & 4278 & 4499 & 2728 & 3929 & 15097 \\
\hline Number of students in science class & 26.67 & 20.60 & 27.99 & 20.33 & 32.72 & 23.94 & 27.73 & 23.98 \\
& $(6.32)$ & $(4.29)$ & $(5.87)$ & $(4.10)$ & $(5.60)$ & $(5.71)$ & $(4.91)$ & $(6.02)$ \\
Observations & 4440 & 4870 & 5960 & 4278 & 4535 & 2728 & 3596 & 14706 \\
\hline Size of cohort (divided by ten) & 5.81 & 4.45 & 5.59 & 11.53 & 8.33 & 3.46 & 5.41 & 10.07 \\
& $(3.00)$ & $(1.98)$ & $(3.24)$ & $(4.62)$ & $(3.86)$ & $(1.58)$ & $(2.97)$ & $(5.50)$
\end{tabular}




\begin{tabular}{|c|c|c|c|c|c|c|c|c|}
\hline Observations & 5053 & 9829 & 6982 & 4282 & 5322 & 2472 & 8352 & 15989 \\
\hline \multirow[t]{2}{*}{ Inhabitants in school district } & 3.24 & 4.01 & 3.44 & 3.76 & 2.70 & 3.68 & 3.14 & 3.51 \\
\hline & $(1.74)$ & $(1.14)$ & $(1.42)$ & $(1.34)$ & $(1.37)$ & $(1.17)$ & $(1.72)$ & $(1.51)$ \\
\hline Observations & 4958 & 9697 & 6684 & 4282 & 5210 & 2630 & 8062 & 15789 \\
\hline \multirow[t]{2}{*}{ Teacher's tenure (years) } & 16.72 & 16.37 & 14.12 & 21.21 & 19.31 & 16.16 & 11.79 & 13.03 \\
\hline & $(9.53)$ & $(9.87)$ & $(10.45)$ & $(9.44)$ & $(9.52)$ & $(12.42)$ & $(9.84)$ & (10.19) \\
\hline Observations & 4568 & 9777 & 6420 & 4282 & 5322 & 2698 & 7599 & 16430 \\
\hline \multirow[t]{2}{*}{ Teacher's education } & 4.99 & 4 & 5.08 & 2.51 & 4.79 & 4.00 & 4.74 & 5.53 \\
\hline & $(0.71)$ & $(0)$ & $(0.27)$ & $(1.12)$ & $(0.69)$ & $(0.31)$ & $(0.63)$ & $(0.50)$ \\
\hline Observations & 4711 & 9849 & 6450 & 4282 & 5288 & 2705 & 7764 & 16318 \\
\hline \multirow[t]{2}{*}{ License to teach ( $1:$ yes, $0:$ no $)$} & 0.82 & 0.98 & 0 & 0.97 & 0.98 & 0 & 0.86 & $(0.86)$ \\
\hline & $(0.39)$ & $(0.15)$ & (0) & $(0.18)$ & $(0.15)$ & $(0)$ & $(0.34)$ & $(0.34)$ \\
\hline Observations & 5219 & 10067 & 8757 & 4282 & 5322 & 2937 & 8502 & 18448 \\
\hline \multirow[t]{2}{*}{ Teacher shortage } & 0.27 & 0.05 & 0.29 & 0.17 & 0.59 & 0.12 & 0.61 & 0.20 \\
\hline & $(0.44)$ & $(0.22)$ & $(0.45)$ & $(0.38)$ & $(0.49)$ & $(0.32)$ & $(0.49)$ & $(0.40)$ \\
\hline Observations & 5083 & 9671 & 7236 & 4282 & 5305 & 2553 & 8270 & 16255 \\
\hline \multirow[t]{2}{*}{ Share of poor families in school } & 1.98 & 1.46 & 2.09 & 1.81 & 1.26 & 1.57 & 2.09 & 2.82 \\
\hline & $(1.11)$ & $(0.83)$ & $(1.14)$ & $(0.89)$ & $(0.51)$ & $(0.99)$ & $(1.21)$ & $(1.25)$ \\
\hline Observations & 5153 & 9857 & 6878 & 4282 & 5182 & 2673 & 7774 & 16557 \\
\hline \multirow[t]{2}{*}{ Share of rich families in school } & 2.05 & 3.49 & 2.45 & 2.11 & 2.96 & 2.98 & 2.39 & 1.92 \\
\hline & $(1.19)$ & $(0.87)$ & $(1.26)$ & $(1.51)$ & $(1.17)$ & $(1.19)$ & $(1.28)$ & $(1.11)$ \\
\hline Observations & 4803 & 9633 & 6624 & 4282 & 5006 & 2542 & 7818 & 15072 \\
\hline
\end{tabular}

Standard deviation in parentheses. Books is a 1-6 index indicating the number of books in the student's home, where 1 is least and 6 is most books. The inhabitants in the school district index run from 1-6, where 1 indicates the largest and 6 the smallest districts. The teacher's education is a 1-6 index indicating the highest education the teacher has finished ( 1 is low, 6 is high). The teacher shortage dummy indicates whether the school to some extent suffers from teacher shortage, and equals one if the principal has reported value 2, 3 or 4 on question 23r. For more details, see the TIMSS background questionnaires: http://timss.bc.edu/timss2003i/context.html.

Table A2. Sensitivity analysis using alternative poor facilities measure. Dummy equal 1 if categories 3 or 4 are chosen

\begin{tabular}{|c|c|c|c|c|c|c|c|c|c|c|c|c|c|c|c|c|}
\hline \multirow{3}{*}{ Variables } & $\underline{\text { Australia }}$ & & Belgium & & $\underline{\mathrm{GB}}$ & & $\underline{\text { Italy }}$ & & $\underline{\text { Japan }}$ & & $\underline{\text { Netherlands }}$ & & $\underline{\mathrm{NZL}}$ & & $\underline{\text { USA }}$ & \\
\hline & (A) & (B) & (C) & (D) & (E) & (F) & (G) & (H) & (I) & (J) & $(\mathrm{K})$ & (L) & (M) & $(\mathrm{N})$ & $(\mathrm{O})$ & (P) \\
\hline & Math & Science & Math & Science & Math & Science & Math & Science & Math & Science & Math & Science & Math & Science & Math & Science \\
\hline \multicolumn{17}{|l|}{ OLS } \\
\hline \multirow[t]{2}{*}{ Alternative pfac } & $-10.70^{*}$ & -6.879 & 2.306 & 4.183 & 6.547 & 4.373 & 10.71 & $13.93^{*}$ & -2.016 & -5.183 & -2.560 & -1.575 & 0.320 & -6.470 & 0.314 & -4.461 \\
\hline & $(5.912)$ & $(5.493)$ & $(3.421)$ & $(2.801)$ & $(6.605)$ & $(5.757)$ & $(7.277)$ & $(7.505)$ & (4.724) & (4.334) & (3.301) & (3.197) & (6.389) & $(5.946)$ & (4.311) & $(4.441)$ \\
\hline R-squared & 0.155 & 0.148 & 0.129 & 0.116 & 0.234 & 0.213 & 0.070 & 0.076 & 0.085 & 0.068 & 0.157 & 0.153 & 0.223 & 0.162 & 0.293 & 0.310 \\
\hline School district controls & + & + & + & + & + & + & + & + & + & + & + & + & + & + & + & + \\
\hline Teacher controls & + & + & + & + & + & + & + & + & + & + & + & + & + & + & + & + \\
\hline Social controls & + & + & + & + & + & + & + & + & + & + & + & + & + & + & + & + \\
\hline No. of schools & 156 & 155 & 134 & 134 & 119 & 120 & 171 & 171 & 136 & 137 & 96 & 96 & 171 & 156 & 172 & 168 \\
\hline No. of students & 3,150 & 3,026 & 4,360 & 4,251 & 3,488 & 3,465 & 3,848 & 3,848 & 3,843 & 3,879 & 1,985 & 1,985 & 2,469 & 2,250 & 10,562 & 10,234 \\
\hline
\end{tabular}

Robust standard errors (adjusted for school level clustering) in parantheses.

$* * * \mathrm{p}<0.01,{ }^{* *} \mathrm{p}<0.05,{ }^{*} \mathrm{p}<0.1$.

Constant term (not reported) included. 


\section{Notes}

Note 1. The countries report results from the cohort with the largest share of nine year old students. For most countries this is the $4^{\text {th }}$ and even though there is some variation across countries, the TIMSS simply refers to this as $4^{\text {th }}$ grade. In Great Britain, schools from England and Scotland are reported separately to the TIMSS database. However, since this analysis is on school level, the number of observations is limited. Thus, I choose to analyze the British data pooled, rather than separating the Scotsmen from the English. Another Western European country, Norway, also participated in the TIMSS 2003. However, the Norwegian data is missing some important socio-economic control variables and I therefore have chosen to not include the Norwegian schools in the analysis.

Note 2. Further details on the practical sampling can be found in Beaton, Mullis, Martin, Gonzales, Kelly, and Smith (1996) and Martin and Kelly (1997).

Note 3. Since it is not obvious how to define a cut-off between good and poor facilities, I in Appendix Table A2 propose an alternative poor facilities dummy. This dummy is equal to 1 only if categories 3 or 4 have been reported. The results are similar to the benchmark results in that they vary across countries but provide less support for the hypothesis that poor facilities have adverse consequences for student achievement. This is not unexpected, given that some facilities that are not in optimal condition are now labeled as "good facilities".

Note 4. This is a dummy equal to 1 if the school is reported too have "some" or "much" shortage of teachers and zero if "no" or "little" problems are reported. The TIMSS 2003 offers a detailed list of other "resource-scarcity" variables. However, including all of them will create noise, and I thus choose to restrict the discussion to the single most important, teachers.

Note 5. See Altonji, Elder, and Taber. (2005) for a formal discussion. 